\title{
Occupational mortality from gastric and duodenal ulcer
}

\section{A SONNENBERG AND G S SONNENBERG}

From the Charles A Dana Research Institute and the Harvard-Thorndike Laboratory of Beth Israel Hospital, Department of Medicine, Division of Gastroenterology, Beth Israel Hospital, Harvard Medical School, Boston, Massachusetts, USA

ABSTRACT The pronounced geographical and temporal variations in gastric and duodenal ulcer suggest that important environmental factors must play a part in their aetiology. To determine the ${ }_{-}^{\omega}$ nature of possible factors, the Registrar General's decennial supplement and the vital statistics 0 . special reports of the United States Department of Health, Education, and Welfare on occupational $\circ$

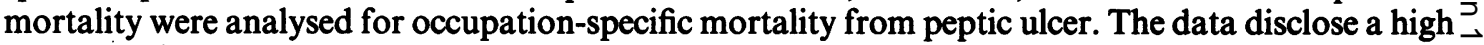
mortality from both types of ulcer among manual workers and a low mortality among sedentary $c$ occupations. This general pattern runs parallel to a low mortality from gastric and duodenal ulcer among the high social classes and a high mortality in the low social classes. Married women displayed a gradient of gastric ulcer mortality increasing from social class 1 to social class 5 but gave $\overrightarrow{.}$ no evidence of social class correlation with respect to duodenal ulcer. The significant correlation $\infty^{\infty}$ between mortality from gastric and duodenal ulcer among different occupations could suggest that ${ }^{\circ}$ both types of ulcer hold some of the precipitating environmental risks in common. In duodenal ulcer the varying extent of energy expenditure among different occupations may be responsible for the different risk of contracting duodenal ulcer and dying from it. The association between energy expenditure and peptic ulcer mortality seems to be less important for gastric ulcer where additional $\stackrel{\odot}{\odot}$ factors associated with social class may also be operating.

The incidence of gastric and duodenal ulcer is characterised by pronounced geographical and temporal variations which suggest that important environmental factors must play a part in the aetiology of both diseases. ${ }^{1-5}$ In the search for relevant environmental factors occupational mortality may provide valuable clues. Apart from the time honoured study on occupational factors in the aetiology of peptic ulcers by Doll and his co-workers, ${ }^{6}$ there are a few reports on the influence of occupation. ${ }^{7-9} \mathrm{~A}$ widespread belief holds that peptic ulcer is related to emotional stress and, therefore, more likely to occur among managers and other professionals. Though peptic ulcer was shown to be frequent among professionals, foremen, and workers holding responsible positions, ${ }^{610-12}$ other evidence seems to suggest the opposite-namely, that peptic ulcer is more common among unskilled labourers and manual occupations. ${ }^{7-91314}$ In their study Doll and his coworkers referred to the Registrar

Accepted 17 June 1985
General's mortality of $1930-2 .^{6}$ The more recent data published on occupational mortality have not been analysed as yet with respect to peptic ulcer. The ${ }_{\odot}^{\circ}$ decennial supplement of the Registrar General of 3 1951 is remarkable for several reasons. ${ }^{15}$ It lists mortality from gastric and duodenal ulcer separately. for 425 occupational groups. In the five calendaro years 1949-53 gastric and duodenal ulcer were recorded as the cause of death in 4886 and 5424 men윽 aged 20-64, respectively. These figures are twice as $>$ high as those of 1959-63 and form a more reliable․ㅡㄹ. basis for statistical analyses than the figures of later $\bar{N}$ periods. ${ }^{1617}$ In 1961 the United States Department of ${ }^{\circ}$ Health, Education, and Welfare published several ${ }^{N}$ reports on occupational mortality in the United $\mathcal{E}^{N}$ States based on vital statistics and census data of $1950 .^{18}$ The American study was designed similarly to the English model of the decennial supplements. The $\frac{\widetilde{D}}{\mathbb{D}}$ existence of two different sets of statistics from $\stackrel{\oplus}{+}$ England and the United States covering the same 0 period gave the additional opportunity to cross check ${ }_{0}^{\circ}$ the validity of correlations found between occupation and mortality. 
Methods

The present study is based on the Registrar General's decennial supplement of 1951 on occupational mortality in England and Wales and the vital statistics special reports of the United States Department of Health, Education, and Welfare. ${ }^{1518}$ The rationale, methodology, and limitations to both studies were explained in detail in separate issues preceding the actual statistical tabulations. By testing whether decedents were reported in the same or different occupational categories in the census and on death certificates, it was found that in both countries about $80 \%$ of the occupations were reported in the same major category. The percentage distribution by major occupational group from the census and the death certificates differed by less than $1 \%$, despite the fact that only $80 \%$ of the population was reported in the same major group in both sources. The errors which account for the discrepancy of the census and mortality data arose from a tendency to omit to mention a former occupation or to use the description "unoccupied" instead of "retired" from a particular occupation. Some discrepancy was due to the lack of correspondence between the "usual" occupation and the "current" occupation reported on the death certificate or in the census. In England there was a tendency to report occupations assignable to social classes 1 and 2 more often at death registration than on the census forms, thus giving rise to an overestimation of death rates in these two classes.

The classification of occupation used by the Registrar General is that used in connection with the 1951 census. The major headings correspond to industrial classifications, and the subheadings to the occupation-that is, the type of work that a person performs. ${ }^{15}$ The American report was based on the intermediate or abbreviated occupational classification published by the United States Bureau of Census. ${ }^{18}$ As opposed to the British classification, the American one puts more weight on the status and the skill of the worker than on his or her industrial allocation. The major headings relate to being a professional, craftsman, foreman, operative, or unskilled labourer, and only the subheadings relate to the industrial character of the work. These differences make the comparison between individual occupations from the British and American classification somewhat difficult. For instance, the British occupational group of turners, machine setters, and shipyard metal machinists could be assigned to the American group of mechanics and repairmen, metal craftsmen, or metal operatives. Since much bias may be introduced by trying to rearrange the American classification according to the British (or vice versa), we report the results separately under the headings used by the governmental agencies of the two different countries.

Each occupational unit was assigned as a whole to one of five social classes: class $1=$ professional occupations, class $2=$ intermediate occupations, class $3=$ skilled occupations, class $4=$ partly skilled occupations, and class $5=$ unskilled occupations. This classification by the Registrar General is based on general standing within the community, education, and economic circumstances. ${ }^{15}$ In the American statistics it was decided to create, on the basis of expert judgement, five socioeconomic classes of occupations, similar in concept to those of the Registrar General.

The Registrar General's decennial supplement also lists mortality of married women arranged according to their husband's occupation and social class. In the present analysis only female mortality of different social classes was analysed. No statistically significant results could be obtained from the female occupational mortality, because only seven (3) of the occupational orders had 30 or more deaths from gastric (duodenal) ulcer attached to them.

In the present analysis only deaths between the ages of 20 and 64 were considered. By applying the age specific death rates from gastric or duodenal ulcer of all men to the census population of one occupational group, the expected number of deaths in the particular occupational group under consideration is calculated. The ratio of observed to expected deaths corresponds to the standardised mortality ratio (SMR) that is normally presented as a percentage. The standard error (SE) of the SMR is SMR/Vobserved deaths. ${ }^{141519}$ When the SMR differed from its expected value of $100 \%$ by more than $1.96 \times \mathrm{SE}$, it was considered significant at the $p$ $<0.05$ level.

\section{Results}

Table 1 shows the standard mortality ratios for gastric and duodenal ulcer in men in England and Wales. If the expected value is $100 \%$ then an " $L$ " was assigned to those occupational orders with an SMR for both gastric and duodenal ulcer lower than $85 \%$, and an " $\mathrm{H}$ " was assigned to those with both values higher than $115 \%$. In England mortality from gastric and duodenal ulcer was low in agricultural occupations; in administrators, directors, and managers; in commercial and finance occupations; and in professional and technical occupations. It was high in painters and decorators and in those engaged in defence service; in entertainment; in personal service; and in unskilled occupations. These results are largely corroborated by the American data which also show a low SMR for professional workers; 
Table 1 Standardised mortality ratio (SMR) and standard error (SE) for gastric and duodenal ulcer in England and Wales

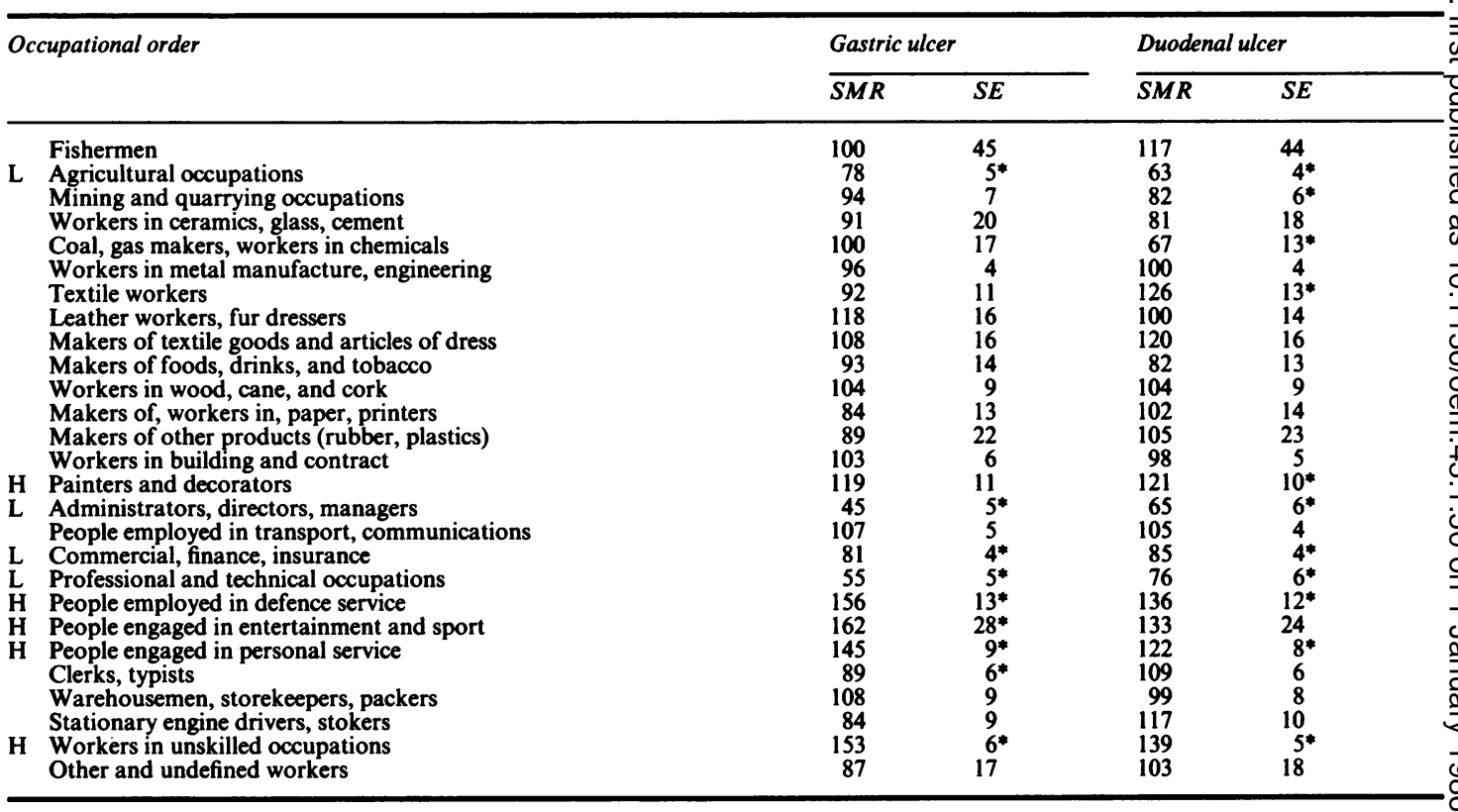

$* \mathrm{p}<0.05$.

$\mathrm{H}=$ Both SMR higher than 115.

$\mathrm{L}=$ Both SMR lower than 85 .

Table 2 Standardised mortality ratio (SMR) and standard error (SE) for gastric and duodenal ulcer in the United States

\begin{tabular}{|c|c|c|c|c|c|c|}
\hline \multirow{2}{*}{\multicolumn{2}{|c|}{ Occupational order }} & \multicolumn{2}{|c|}{ Gastric ulcer } & \multicolumn{2}{|c|}{ Duodenal ulcer } & \multirow{2}{*}{$\begin{array}{l}\text { Work } \\
\text { load }\end{array}$} \\
\hline & & $S M R$ & $S E$ & $\overline{S M R}$ & $S E$ & \\
\hline \multicolumn{2}{|r|}{$\begin{array}{l}\text { L Professional workers } \\
\text { All other professional, technical, and kindred workers } \\
\text { L Officials, inspectors, and specified managers } \\
\text { Managers, officials, and proprietors, wholesale } \\
\text { and retail trade } \\
\text { Clerical and kindred workers } \\
\text { Salesmen and sales clerks, retail trade } \\
\text { All other sales workers } \\
\text { Mechanics and repairmen } \\
\text { L Foremen } \\
\text { H Metal craftsmen } \\
\text { Engine and construction machinery operators } \\
\text { Cabinetmakers and carpenters } \\
\text { All other craftsmen } \\
\text { Transportation and public utility workers } \\
\text { Guards and protective service workers } \\
\text { H Painters and plasterers } \\
\text { Metal operatives } \\
\text { Drivers and deliverymen } \\
\text { Operatives in selected manufacturing industries } \\
\text { H Mine operatives and labourers } \\
\text { All other operatives } \\
\text { H Service workers } \\
\text { H Labourers in metal manufacturing } \\
\text { H Labourers in other manufacturing } \\
\text { H Construction and outdoor labourers } \\
\text { Habourers in other non-manufacturing industries } \\
\text { Agricultural workers }\end{array}$} & $\begin{array}{r}84 \\
96 \\
102 \\
92 \\
97 \\
48 \\
134 \\
103 \\
72 \\
111 \\
100 \\
94 \\
165 \\
64 \\
132 \\
76 \\
230 \\
104 \\
141 \\
215 \\
241 \\
126 \\
149 \\
96\end{array}$ & $\begin{array}{c}8 \\
10 \\
15 \\
12 \\
12 \\
10^{*} \\
13^{*} \\
18 \\
11^{*} \\
12 \\
19 \\
16 \\
21^{*} \\
9 * \\
13^{*} \\
99^{*} \\
29^{*} \\
14 \\
15^{*} \\
33^{*} \\
30^{*} \\
14 \\
12^{*} \\
6\end{array}$ & $\begin{array}{r}106 \\
115 \\
140 \\
124 \\
80 \\
84 \\
129 \\
96 \\
95 \\
137 \\
96 \\
181 \\
130 \\
85 \\
104 \\
100 \\
117 \\
82 \\
119 \\
189 \\
152 \\
111 \\
136 \\
70\end{array}$ & $\begin{array}{l}10 \\
11 \\
18^{*} \\
15 \\
11 \\
14 \\
14^{*} \\
18 \\
13 \\
14^{*} \\
20 \\
24^{*} \\
20 \\
11 \\
12 \\
11 \\
22 \\
13 \\
14 \\
32^{*} \\
25^{*} \\
14 \\
12^{*} \\
5^{*}\end{array}$ & $\begin{array}{l}1 \\
3 \\
3 \\
2 \\
3 \\
2 \\
4 \\
2 \\
3 \\
4 \\
3 \\
2 \\
3 \\
5 \\
3 \\
4 \\
5 \\
4 \\
4 \\
5 \\
5 \\
5 \\
5 \\
2\end{array}$ \\
\hline \multicolumn{7}{|c|}{$\begin{array}{l}{ }^{*} \mathrm{p}<0.05 \\
\mathrm{H}=\text { Both SMR higher than } 115 . \\
\mathrm{L}=\text { Both SMR lower than } 85 .\end{array}$} \\
\hline
\end{tabular}


officials, inspectors, and managers; and foremen. In American agricultural workers the SMR for duodenal but not gastric ulcer was low. As in England and Wales, the SMR was high in painters and plasterers, service workers, and labourers (unskilled workers) in any industry. In both countries there was a significant linear correlation between the SMR for gastric and duodenal ulcer (figs 1 and 2). The SMR for gastric ulcer indicates a strong gradient increasing from social class 1 to social class 5 (fig 3). Duodenal ulcer displayed a less pronounced social distribution with the same general tendency of prevalence, low in the high social classes and high in the low social classes. These observations apply to both countries. Married women displayed a rise of gastric ulcer mortality moving from the first to the fifth class but gave no evidence of social class correlation with respect to duodenal ulcer (fig 4).

\section{Discussion}

The analysis of occupational mortality from gastric and duodenal ulcer shows a high mortality from both among manual workers and a low mortality among sedentary occupations. This general pattern runs parallel to a low mortality from gastric and duodenal ulcer among the high social classes and a high mortality in the low social classes. In addition, there is a high mortality of peptic ulcer among painters and a low mortality among agricultural workers that may not fit the general pattern outlined above. The wideheld belief of peptic ulcer being a disease of professionals, managers, and foremen under stress is obviously wrong according to the English and

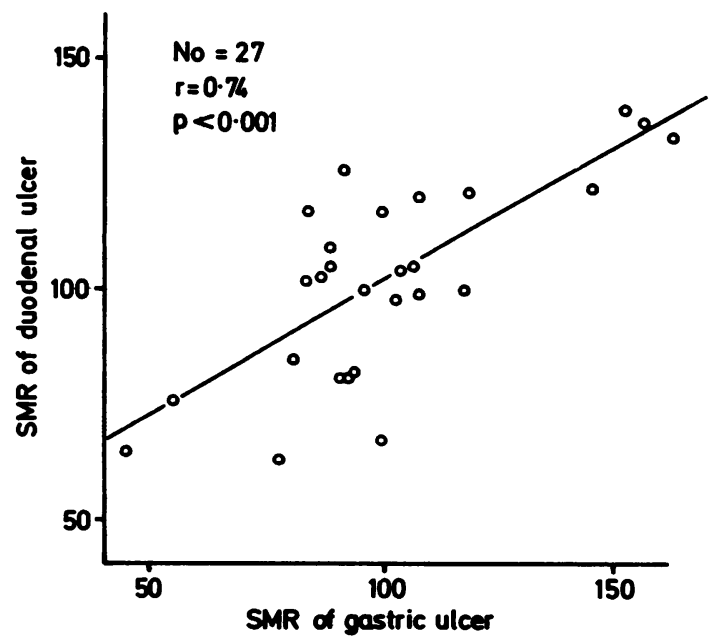

Fig 1 Linear regression between SMRs for gastric and duodenal ulcer in England and Wales; same data as in table 1.

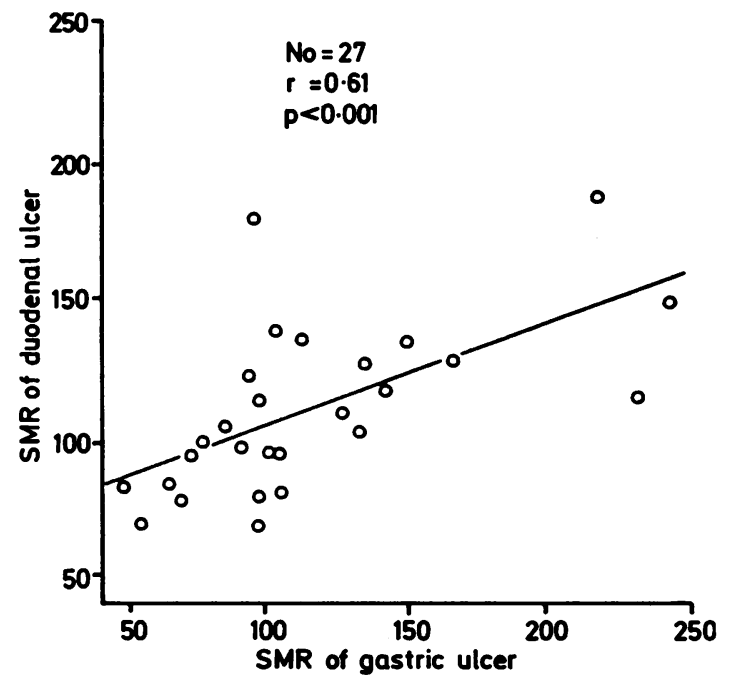

Fig 2 Linear regression between SMRs for gastric and duodenal ulcer in United States; same data as in table 2.

American statistics for the period 1949-53. In the Registrar General's decennial supplements of 1921 and 1931 duodenal but not gastric ulcer was more evenly distributed among the five social classes. ${ }^{2021}$ Even in the older statistics, however, the distribution of duodenal ulcer was never so clear cut as to make it a "manager's disease."

The data from the decennial supplement and special report partly support some of the older studies which, however, were based on a much lower number of cases. Ihre and Müller in their series also noted an appreciably lower proportion of ulcers among intellectuals. ${ }^{8}$ The occupational survey carried out by Doll and his colleagues showed a high prevalence of peptic ulcer among doctors, executives, and foremen and a low incidence among agricultural workers and sedentary workers such as civil servants, scientists, and draughtsmen. ${ }^{6}$ The data reported by Pulvertaft and Langman also suggested that duodenal ulcer was more common among unskilled workers. ${ }^{1314}$

A straightforward interpretation of the results would indicate that it is physical work itself that somehow increases the risk of dying from peptic ulcer. To maintain a balanced energy turnover someone with increased energy consumption during work needs more food. It may be speculated that any steady increase in food consumption (not just a temporary one as in gaining weight) leads to some structural changes in the upper gastrointestinal tract that makes it more susceptible to developing a peptic ulcer. The measurement of average daily energy expenditure in the individual occupation has many difficulties. ${ }^{22-24}$ Though it may be easy to measure 


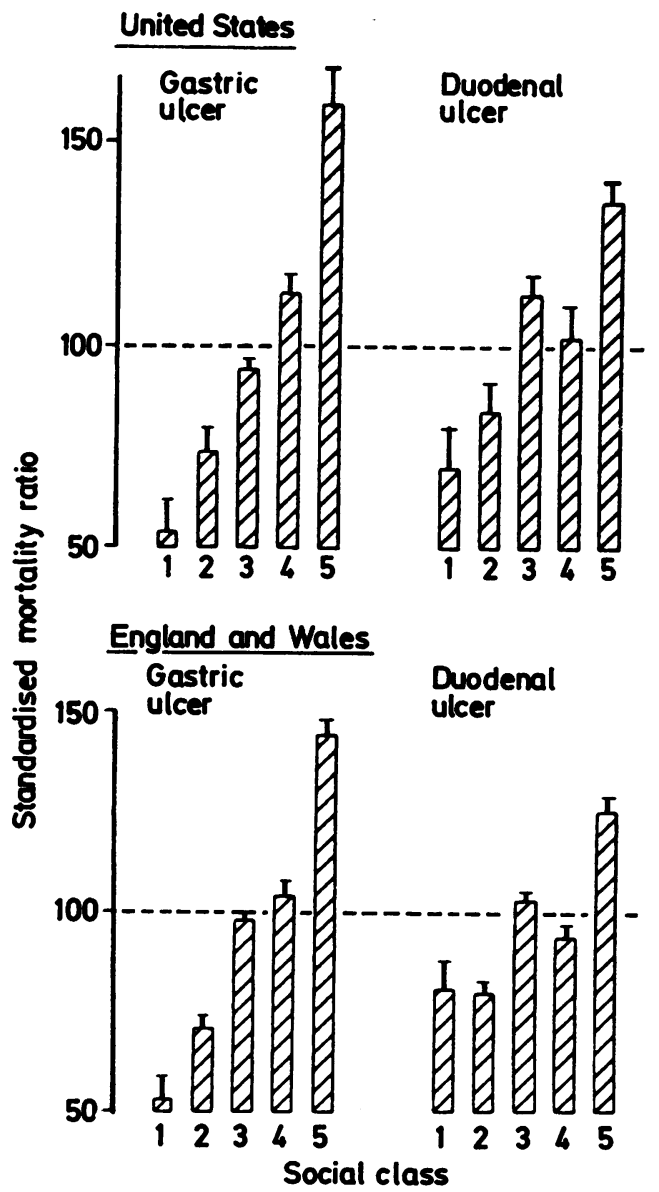

Fig 3 SMR ( \pm standard error) for gastric and duodenal ulcer in the five social classes, 1 and 5 corresponding to highest and lowest social class.

the energy expenditure associated with specific activities such as drilling, shovelling, or hewing, a determination of the actual daily workload is limited by recording the time distribution spent on different activities during a workday rather than on the exact values of different activities. ${ }^{22-24}$ People nominally having the same occupation may nevertheless differ largely in the actual amount of energy they spend during their working hours. Matters become even more complicated when allied occupations are grouped into one occupational order. Assigning different rates of daily energy expenditures to different occupational orders, therefore, cannot be more than an intelligent guess. Based on a table published by Passmore and Draper, ${ }^{22}$ we have tried to assign ranks between 1 and 5 to the occupations in the abbreviated American classification of

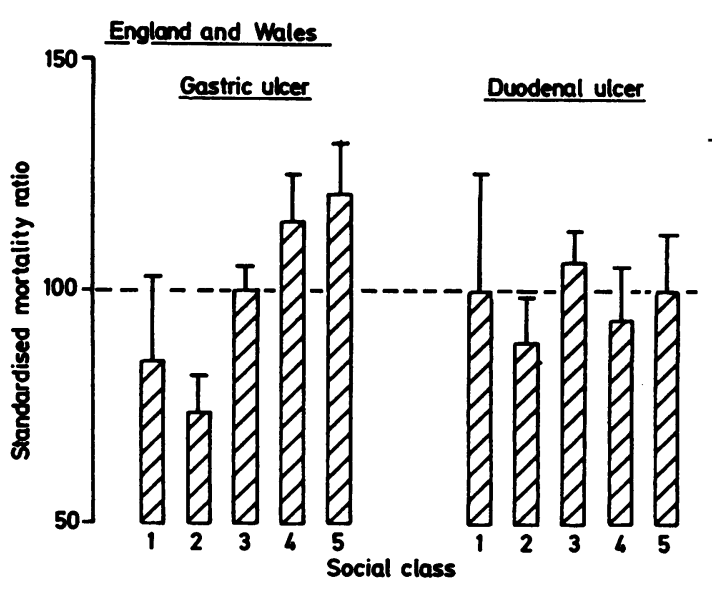

Fig 4 SMR ( \pm standard error) for gastric and duodenal ulcer in married women in England and Wales plotted against their husbands' social class.

occupations. It may well be that some of our ranks underestimate or overestimate the true workload by one degree-for example, metal craftsmen deserving $\vec{\theta}$ rank 3 instead of 4 . In the present context they are not ${ }_{\infty}^{\circ}$ introduced as scientific proof but rather to illustrate the possibility that energy expenditure might be one environmental factor associated with the risk of developing peptic ulcer (fig 5).

The data of figure 5 may look convincing with respect to duodenal ulcer. Two important exceptions $\triangle$ should be noted, however. Firstly, security guards $\overrightarrow{\overrightarrow{0}}$ show an unduly high prevalence of gastric and 3 duodenal ulcer. In the American and English civilian defence service this may reflect the selective transfer of individuals who have developed disability due to peptic ulcer to less strenuous occupations. This $\stackrel{\mathbb{D}}{3}$ explanation, however, does not apply to the British armed forces, which also showed increased mortality from both types of ulcer (in the American $\delta$ occupational mortality statistics, the armed forces $₹$ were not included). Secondly, despite a presumably 을 high energy expenditure in British miners, ${ }^{25}$ they have a low mortality rate resulting from duodenal ulcer.

The association between energy expenditure and mortality seems to be stronger with duodenal than $O$ with gastric ulcer. The significant correlation between $N$ occupational mortality from gastric and duodenal ్ㅣㅇ ulcer could suggest that both ulcer types hold some 0 of the precipitating environmental risks in common. Though on average the SMR for gastric ulcer also increases with increased workload, the gastric ulcer $\stackrel{\oplus}{\rightarrow}$ data show a pronounced scatter, indicating that 0 additional factors must play a part. These factors seem to be related to the social status, and two hints $\mathbb{D}$ support this contention. Firstly, the SMR for gastric 


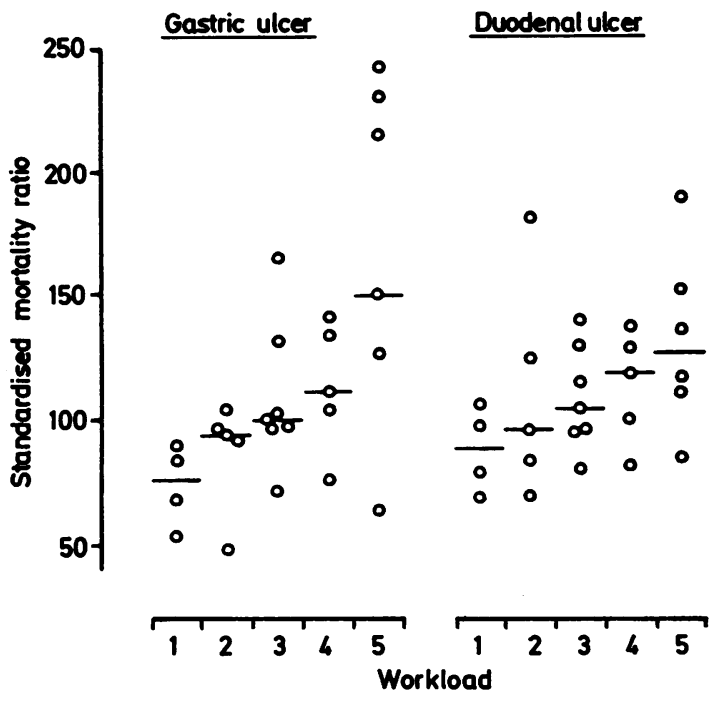

Fig $5 S M R$ for gastric and duodenal ulcer plotted against workload of different occupations assigned a rank value between 1 (low) and 5 (high); same data as in table 2.

ulcer is more strongly associated with the social gradient than duodenal ulcer. Secondly, whereas the social class gradient is unequivocally preserved in the female mortality from gastric ulcer, it no longer exists in duodenal ulcer. This again may indicate that in duodenal ulcer the social gradient predominantly reflects the amount of physical work that, unlike the social gradient, is not transferred to married women.

In conclusion, the analysis of the occupational mortality in England and Wales and in the United States shows that mortality from both types of ulcer is rare among sedentary occupations and frequent among occupations associated with manual work. In duodenal ulcer the varying extent of energy expenditure among different occupations may be responsible for the different risk of contracting duodenal ulcer and dying from it. In gastric ulcer additional factors somehow associated with the social class seem also to be operating.

This study was supported by grant No 172/1-1 from the Deutsche Forschungsgemeinschaft. We thank Edith M Kimball, government librarian of the Francis A Countway Library of Medicine, Harvard Medical School, for her help in assembling the data and Jackie Solberg for editorial help.

\section{References}

${ }^{1}$ Jennings D. Perforated peptic ulcer. Changes in age-incidence and sex-distribution during the last 150 years, parts I and II. Lancet 1940;i:395-8, 444-7.

${ }^{2}$ Susser M. Causes of peptic ulcer. A selective epidemiologic review. J Chronic Dis 1967;20:435-56.

${ }^{3}$ Coggon D, Lambert P, Langman MJS. 20 years of hospital admissions for peptic ulcer in England and Wales. Lancet 1981;i: $1302-4$.

${ }^{4}$ Sonnenberg A. Occurrence of a cohort phenomenon in peptic ulcer mortality from Switzerland. Gastroenterology 1984;86:398-401.

${ }^{5}$ Sonnenberg A. Geographic and temporal variations in the occurrence of peptic ulcer disease. Scand J Gastroenterol 1985;20, suppl 110:11-24.

${ }^{6}$ Doll R, Avery Jones F, Buckatzsch MM. Occupational factors in the aetiology of gastric and duodenal ulcers with an estimate of their incidence in the general population. London: HMSO, 1951. (Medical Research Council special report series, No 276.)

${ }^{7}$ Jennison J. Observations made on a group of employees with duodenal ulcer. Am J Med Sci 1938;196:654-62.

${ }^{8}$ Ihre JE, Müller R. Gastric and duodenal ulcer. Study of 1193 cases collected during 1930 to 1940 in Stockholm. Acta Med Scand 1943;116:33-57.

${ }^{9}$ Sallström T. Regarding occupational factors in gastric ulcer and duodenal ulcer. Acta Med Scand 1945;120:340-8.

${ }^{10}$ Monson RR, MacMahon B. Peptic ulcer in Massachusetts physicians. N Engl J Med 1969;281:11-5.

${ }^{11}$ Dunn JP, Cobb S. Frequency of peptic ulcer among executives, craftsmen, and foremen. J Occup Med 1962;4:343-8.

${ }^{12}$ Cobb S, Rose RM. Hypertension, peptic ulcer, and diabetes in air traffic controllers. JAMA 1973;224:489-92.

${ }^{13}$ Pulvertaft CN. Comments on the incidence and natural history of gastric and duodenal ulcers. Postgrad Med J 1968;44:597-602.

${ }^{14}$ Langman MJS. The epidemiology of chronic digestive disease. London: Edward Arnold Publishers, 1979.

${ }^{15}$ Registrar General. The Registrar General's decennial supplement England and Wales 1951-occupational mortality, parts I and II. London: HMSO, 1958.

${ }^{16}$ Registrar General. The Registrar General's decennial supplement England and Wales 1961 -occupational mortality tables. London: HMSO, 1971.

${ }^{17}$ Office of Population Censuses and Surveys. Occupational mortality. The Registrar General's decennial supplement England and Wales 1970-72. London: HMSO, 1978. (Series DS No 1.)

${ }^{18}$ US Department of Health, Education, and Welfare. Vital statistics-special reports. Vol 53, No 1-5. Washington: USDHEW, 1961-3.

${ }^{19} \mathrm{Kahn}$ HA. An introduction to epidemiologic methods. New York: Oxford University Press, 1983.

${ }^{20}$ Registrar General. The Registrar General's decennial supplement England and Wales 1921. London: HMSO, 1927.

${ }^{21}$ Registrar General. The Registrar General's decennial supplement England and Wales 1931-occupational mortality. London: HMSO, 1936.

${ }^{22}$ Passmore R, Draper MH. Energy metabolism. In: Albanese AA, ed. Newer methods of nutritional biochemistry. Vol 2. New York: Academic Press, 1965:41-83.

${ }^{23}$ Durnin JVGA, Passmore R. Energy, work, and leisure. London: Heinemann Educational Books Ltd, 1967.

${ }^{24}$ Spitzer H, Hettinger T, Kaminsky G. Tafeln für den Energieumsatz bei körperlicher Arbeit. 6th ed. Berlin: Beuth Verlag, 1982.

${ }^{25}$ Garry RC, Passmore R, Warnock GM, Durnin JVGA. Expenditure of energy and the consumption of food by miners and clerks, Fife, Scotland, 1952. London: HMSO, 1955. (Medical Research Council special report series, No 289.) 